\title{
MIRÓ Y DICKENS; UNA POSIBLE RELACIÓN*
}

Una relectura reciente de David Copperfield, libro predilecto de mi infancia, leído y vuelto a leer entonces con insistente devoción, llevó mi pensamiento inmediatamente hacia otras dos obras bien conocidas por mí actualmente: Nuestro Padre San Daniel y El obispo leproso. No me refiero a toda la novela de Dickens, naturalmente, sino a los primeros capítulos, por donde transitan ciertas figuras con semejanzas notables con otras, parte integrante de las obras de Miró.

Mi primer impulso fue revisar los catálogos existentes de los libros que formaron parte de la biblioteca particular de Miró. Ni en el catálogo familiar, realizado probablemente por su hija Clemencia (cuya copia está en mi poder), ni en la obra de Macdonald $^{1}$ aparece ninguna obra de Dickens. Claro que al final del catálogo se anota claramente que: "Muchos libros pasaron a la biblioteca de Emilio. Algunos se regalaron a amigos de Gabriel Miró". Algo semejante afirma Macdonald ${ }^{2}$.

En un reciente viaje a España (octubre de 1987) pude ponerme en contacto con Olympia Luengo, nieta del escritor. Ella recordaba varias obras de Dickens en la biblioteca de su abuelo, las cuales, efectivamente, habían pasado a la colección de la casa de campo de su hermano Emilio. Incluso creía recordar que se trataba de las ediciones de Ramón Sopena, es decir, de las ediciones

* Ponencia leída en la 41st Annual Kentucky Foreign Language Conference, University of Kentucky, Lexington, 21-23 de abril, 1988. No se publican actas.

${ }^{1}$ IAn Macdonald, Gabriel Miró: His private library and his literary background, Tamesis Books, London, 1975.

2 "When one compares Clemencia's list in detail with the library, a certain number of discrepancies appear - books listed by Clemencia have disappeard, others that obviously belonged to Miró are not listed', ibid., p. 39. 
en español, ya que Miró no leía inglés. Pero para mi desencanto, supe que la casa de Emilio sufrió un incendio hace pocos años y en él desapareció casi por completo la biblioteca. No hay rastros, por lo tanto, de las obras de Dickens que Miró pudiera haber leído.

Pero todo esto es un poco anecdótico. No es indispensable constatar las posesiones bibliográficas de un escritor para conocer sus gustos y sus fuentes. Tampoco estoy tratando de demostrar que Dickens influyera determinantemente en Miró. Pero, eso sí, no me cabe la menor duda de que existe una relación entre una serie de situaciones y de personajes del escritor inglés y de otras del español, lo cual voy a tratar de mostrar en estas páginas.

Sería también difícil de precisar hasta qué punto Miró se inspiró conscientemente en los personajes o en los hechos de David Copperfield. Por lo siniestramente llamativo de ciertas partes de la narración más bien me inclinaría a pensar que, de alguna forma, la sensibilidad del escritor quedaría herida por ellas, de tal manera que su huella pudiese aflorar en cualquier momento y reflejarse así en su obra. Proceso éste que ya fue descrito por Freud, al referirse a las circunstancias de la creación: "Un poderoso suceso actual despierta en el poeta el recuerdo de un suceso anterior, perteneciente casi siempre a su infancia, y de éste parte entonces el deseo, que se crea satisfacción en la obra poética, la cual deja ver elementos tanto de la ocasión reciente como del antiguo recuerdo"'3.

Podría considerarse que Nuestro Padre San Daniel y El obispo leproso son dos novelas sin protagonista. Pero entre los muchos seres que las pueblan, y tantos de personalidad sobresaliente, hay tres que atraen poderosamente la atención: Paulina Egea, por su deliciosa simplicidad y su belleza; Álvaro Galindo, que se convierte en su marido, por su torva existencia, y la hermana de éste, de aristas agudas, que vivirá con la pareja apenas recién casados. Pablo, el niño que nace al final de Nuestro Padre San Daniel, no revela su personalidad hasta $E l$ obispo leproso.

Álvaro, Paulina y Elvira constituyen, en un principio, una familia peculiar; en la vida conyugal de los dos primeros se introduce Elvira, desde que aquella se inicia. El contraste entre las dos mujeres es evidente: Paulina es linda, dulce, sumisa, refinada. Elvira es fea, tensa, imperativa, áspera. Su cabello es "lacio y ne-

${ }^{3}$ Sigmund Freud, "El poeta y la fantasía", en Psicoanálisis aplicado, Alianza, Madrid, 1972, p. 17. 
grísimo"4. La relación entre ambas parece imposible; sin embargo, Paulina acepta resignada, sin quejas aparentes. Elvira impone su voluntad y maneja el hogar.

Un triángulo semejante inicia la narración en David Copperfield $^{5}$. Al establecerse el matrimonio entre Eduardo Murdstone y la linda viuda Clara Copperfield, Juana Murdstone, hermana de Eduardo, llega a vivir con ellos. La imagen de esta mujer, muy parecida físicamente a su hermano, tiene puntos comunes con la de Elvira: cabellos negros, cejas espesas que parecieran las patillas de su hermano colocadas en la cara, nariz imperativa y una presencia "metálica" en todas sus actitudes 6 .

La sensación "metálica" la perciben los sobrinos de ambas mujeres como una presencia vívida: "Ese estridor de llaves y cerraduras creía sentirlo Pablo hasta con la lengua, amarga por el relumbre del agua oxidada..."7.

La misma sensación, casi táctil y común, produce la ropa de las dos mujeres: el vestido de la señorita Murdstone "de terciopelo negro, que parece cortado de un paño mortuorio" " $(D C, \mathrm{t}$. 1 , p. 53) y Elvira "rígida de sedas viejas" (NPSD, p. 758). Negros también, $\mathrm{y}$ sin descanso, son los ojos de ambas: los de la señorita Murdstone "paseando por toda la iglesia" ( $D C$, p. 53), y los de Elvira, que "cansaban de inquietud" (NPSD, p. 754).

Pero donde tienen puntos comunes, en verdad sorprendentes, estas dos mujeres, es en la personalidad. En las dos novelas, tanto en David Copperfield como en Nuestro Padre San Daniel (y El obispo leproso), ambas parecen descritas con pinceladas muy rápidas, que son sin embargo suficientes para llegar a proporcionar un buen retrato. Ambas, como perfectas amas de casa, se caracterizan por una inquietud constante, que las mantiene indefinidamente en tensión, a la que se mezcla un sentimiento de des-

${ }^{4}$ Gabriel Miró, Nuestro Padre San Daniel en Obras Completas, Biblioteca Nueva, Madrid, 1943, p. 754. En adelante cito por esta edición anotando entre paréntesis $N P S D$ y las páginas.

${ }^{5} \mathrm{Me}$ ha sido imposible encontrar la traducción de Ramón Sopena de los años veinte. Lo más próximo a mi alcance ha sido la del mismo editor, de 1959. No creo que haya diferencias sustanciales, ya que ésta es una reedición, donde ni siquiera aparece el nombre del traductor.

${ }^{6}$ Carlos Dickens, David Copperfield, Sopena, Barcelona, 1959, t. 1, p. 49. En adelante cito por esta edición, anotando entre paréntesis $D C$, tomo y la página o páginas.

${ }^{7}$ Gabriel Miró, El obispo leproso en Obras Completas, Biblioteca Nueva, Madrid, 1943, p. 814. En adelante cito por esta edición, anotando entre paréntesis $O L$ y la página o páginas. 
confianza. Juana Murdstone es comparada por su "sobrino" con una alondra, por su puntualidad en levantarse con el sol $(D C, \mathrm{t}$. 1, p. 50). Desde que se incorpora a la vida familiar de su hermano no cesa de poner orden - un nuevo orden - en la casa donde llega. Su propia cuñada alaba, tal vez con cierta reticencia, este incesante quehacer de la señorita Murdstone:

¿No está trabajando desde que amanece hasta que se pone el sol? ¿No vigila todo, la carbonera, la repostería, la despensa y hasta los sitios más desagradables? ( $D C$, t. 1, p. 115).

La misma inquietud es, tal vez, lo que más singulariza a Elvira Galindo. Retomo aquí las palabras de Miró, que la recortan de manera magistral:

No podía. Nunca sosegaba. Los armarios, las cómodas, el arcón de harina, las alacenas y despensa, todo se abría, se cerraba, se contaba bajo el poder, la vigilancia y las llaves de la señorita Galindo $(O L$, p. 814).

De la misma manera, ambas mujeres comparten otra obsesión: alguien las observa sin que se den cuenta y es necesario localizar a dicho personaje. Juana Murdstone sospecha que son las criadas quienes ocultan a un individuo, $y$, a horas intempestivas, recorre las despensas, los armarios, la leñera. Y no obstante no encontrar a nadie sigue "persuadida de que allí se ocultaba a alguien" ( $D C$, p. 50$)$. Ésa era una de las causas que la llevaban a levantarse por las mañanas antes de que nadie lo hiciera: su preocupación "por la idea de encontrar al hombre oculto" (loc. cit.). Elvira Galindo "se abrasaba en la desconfianza como en un amor infinito. Si una puerta se quedaba entornada, temía el acecho de unos ojos enemigos" (OL, p. 815).

Para redondear esta visión conjunta de las dos mujeres se presenta un elemento que se podría tomar como simbólico, y que ambas manejan con singular destreza: las llaves. Una vez que Juana Murdstone toma posesión de su nueva casa, se apodera de ellas para no separarse más:

A partir de aquel momento, la señorita Murdstone guardó las llaves en su bolso de acero durante el día y bajo la almohada durante la noche...(DC, t. 1, p. 50$)$. 
La imagen de Elvira Galindo aparece frecuentemente enlazada a la de las llaves, que siempre le acompañan: juguetea con el llavero que pende de la correa de su hábito de los Dolores, ropa que usualmente viste (NPSD, p. 771), y lo empuña como una vara de mando para establecer su imperio: "[todo] se contaba bajo el poder, la vigilancia y las llaves de la señorita Galindo"' $(O L$, p. 814).

Si nos ayudamos un poco del psicoanálisis podremos observar lo bien trazado de estas dos personalidades, así como la profundidad de sus semejanzas. Los dos escritores tienen en mente dos figuras con una patología muy claramente presentada. Su dedicación obsesiva por las tareas domésticas permite establecer una neurosis (hoy bien delimitada ya). $\mathrm{El}$ afán de dominio con las personas que quedan bajo su férula es evidente. Dos comportamientos que conducen a lo que Adler denominó "protesta viril"', que se podría resumir como un deseo femenino de querer igualar al hombre, es decir, de modificar una forma impuesta por la realidad. No me parece difícil suponer que los dos escritores tuvieran presente este rasgo de sus figuras, ya que Dickens describe a su personaje desde el principio con rasgos marcadamente viriloides, como una segunda edición de su hermano, y Miró hace algo semejante con Elvira. Éste, además, permite al lector intuir tendencias homosexuales en Elvira Galindo, que son, al mismo tiempo, identificación con el hermano admirado. Ante la belleza de Paulina, recién convertida en madre, los dos hermanos reaccionan de manera semejante: una atracción física casi insoportable por la hermosura de la mujer, que parece ser más fuerte que sus voluntades reprimidas. "Elvira se puso a su espalda [de Paulina] y aspiró el perfume de su respiración. Le pareció sentirla como hombre" (NPSD, p. 804).

También es importante recordar el significado simbólico del término "llave", el objeto que las dos damas esgrimen, que las acompaña constantemente y con el cual ejercen su vigilancia. Su simbolismo fálico contribuye a determinar las características masculinas y la voluntad de imperio, tendencias comunes a las dos.

Otra circunstancia coincidente de las dos narraciones me parece significativa. Las dos esposas, débiles y sometidas, que en un principio celebran la llegada del nuevo miembro de la familia, ofrecen más tarde una cierta resistencia ante el gobierno indiscutible de la cuñada intrusa. Resistencia inútil, que muy pronto que-

${ }^{8}$ Alfred Adler, El carácter neurótico, Paidós, Barcelona-Buenos AiresMéxico, 1984, p. 233 
da apagada por el imperio absoluto de las recién llegadas, apoyado sin restricciones por los dos maridos. La palabra "hermana", que se pronuncia al entablarse la relación, desaparece casi inmediatamente. La misma línea de fortaleza y eficiencia es expresada por las dos advenedizas, que se apresuran a observar los ángulos frágiles e infantiles de sus dos cuñadas o, lo que es lo mismo, su incapacidad - manifiestan aquellas - para regir y gobernar una casa:

Clara, hermana mía, - dice la señorita Murdstone- sabes que he venido a esta casa para ahorrarte molestias. Eres demasiado linda y muy niña (mi madre se ruborizó y pagó con una sonrisa el cumplido) para ocuparte en los menesteres que yo puedo ocupar en tu lugar ( $D C$, t. 1, p. 50$)$.

"- ¡No te imaginaba yo tan linda y tan fina!", exclama Elvira al conocer a Paulina; "Nunca el elogio de su belleza la enterneció y la sofocó tanto como ahora recibiéndolo de aquella mujer' (NPSD, p. 755).

Cuando las nuevas situaciones quedan establecidas, se produce una natural reacción de rechazo en las dos esposas relegadas, manifestada con cierta timidez. Una sola vez, por parte de cada una, hay un intento de rebelión. Clara Copperfield llora pidiendo ser tenida en cuenta. Paulina "una vez quiso mitigar ese ávido gobierno, y se puso muy dolida la hermana del marido" (OL, p. 815). La reacción de las dos cuñadas, hiperinflada, saturada de reproches y de amenazas de abandono, es semejante. Similar es, también, la conducta de los dos maridos en esta ocasión: ambos comparten la ofensa con sus hermanas y toman un claro partido a favor de ellas. "Cuando veo que se trata con grosería a Juana Murdstone, mi afecto se enfría de una manera muy sensible" ( $D C$, t. 1, p. 52), advierte Eduardo Murdstone a su esposa. Álvaro Galindo toma a su hermana por los hombros "acercándosela con ansiedad devota" y su pensamiento se hace visible: "¡Echar a esa hermana de supremas virtudes!" (OL, p. 815).

Todo lo anterior muestra las coincidencias de dos situaciones paralelas: dos triángulos familiares, donde probablemente la verdadera pareja está constituida por los dos hermanos, mientras que las esposas quedan postergadas a un plano inferior. Puesto que éstas son psíquicamente más frágiles, van siendo relegadas a una posición secundaria. Por si no queda suficientemente claro, Miró resalta la situación por boca de Pablo, el hijo de los Galindo: "—En 
mi casa siempre llora la mamá. Es que la mujer y el marido parecen los otros dos" (OL, p. 811).

La austeridad y la forma en que practican la religión delimita el estilo de estos dos núcleos familiares. "La entereza", la gran virtud que caracteriza a los Murdstone y de la que continuamente se enorgullecen:

La aspereza de carácter de los Murdstone se manifestaba también en su religión, que era austera e inexorable, tanto que yo he creído después que tal severidad era la consecuencia necesaria de la entereza del señor Murdstone ( $D C$, t. 1, p. 53$)$.

Álvaro Galindo "se complacía en la fiereza de su virtud amarga" (NPSD, p. 781). La rigidez, tanto en el comportamiento mundano, como en la forma de comprender la religión, es uno de los grandes temas de las novelas de Miró, siempre en contraste con la suavidad sensual de Paulina y su forma diferente de experimentar la religión.

Dickens hace ver cómo la intransigencia religiosa de los Murdstone sobrepasa los postulados espirituales del propio pastor. El niño David se pregunta

si nuestro pastor estará equivocado y tendrán en cambio razón los hermanos Murdstone cuando afirman que todos los ángeles del cielo son ángeles exterminadores ( $D C$, pp. 53-54).

La religión de Álvaro y Elvira Galindo es de una dureza equivalente:

¡Hombre puro, que siempre tiene a Dios en su boca! ¡Dios de don Álvaro, Dios de doña Elvira! [ . . ] ¡Más puro y rígido el Dios de don Álvaro que el mismo don Álvaro! ¡Ay don Magín, y qué Dios tan terrible! ¡Dios nos libre de ése! (OL, p. 853).

Juana y Elvira comparten su afición por perseguir a los pecadores. Las dos, al rezar, se singularizan por el énfasis al articular sus eses; la primera "sisea sus oraciones acentuando con energía cruel las palabras más terribles" $(D C$, t. 1, p. 53); Elvira se confiesa en forma de "diálogo apasionado y profuso, con un silbo de eses largas, con nombres rotos". Y ambas acusan. Cuando Juana pronuncia la frase "miserables pecadores", recorre la iglesia con los ojos, "como si llamase por su nombre a todos los individuos de la feligresía" ( $D C$, t. 1, p. 53). Elvira sí pronuncia los 
nombres en su confesión, "el de don Álvaro, el de Paulina, el de Purita, el de Lóriz, el de don Magín..." (NPSD, p. 806).

En el camino hacia la iglesia, los dos autores describen una imagen semejante en la manera de organizarse ambas familias: la esposa caminando en medio de los dos hermanos, en una posición que podría simbolizar el lugar de un reo; delante la señorita Murdstone, la esposa a continuación y el marido cerrando el paso (cf. ' $D C$, t. 1, p. 53). Paulina va también "entre el esposo y la hermana"' (NPSD, p. 803).

No es mi intención establecer una comparación directa entre los personajes de las tres novelas. Aunque sí se pueden percibir muchos detalles comunes entre Juana Murdstone y Elvira Galindo, sería muy difícil encontrar más que generalidades en los casos de Clara-Paulina y Eduardo-Álvaro. Es más bien la situación triangular la que se repite con coincidencias curiosas e interesantes. Además, hay diferencias sustanciales en lo que se refiere a la importancia de los personajes en estas obras: la familia Murdstone aparece sólo en los primeros capítulos de la novela, para desaparecer casi totalmente en el desarrollo posterior. En cambio los Galindo son una especie de columna vertebral en Nuestro Padre San'Daniel y El obispo leproso. Sin embargo creo que los Murdstone debieron de imprimir honda huella en Gabriel Miró durante alguna etapa de su vida.

Pero hay todavía un elemento más que enlaza estos dos triángulos, una cuarta esquina y de gran importancia: el niño de ambas familias. Tampoco David y Pablo Galindo son figuras semejantes, del mismo modo que sus historias difieren absolutamente. Pero su posición infantil dentro del triángulo familiar es determinante, porque ambos, además de ser observadores de la situación, son.jueces también, personajes que ayudan al lector en la comprensión de los hechos, con simpatías y antipatías muy claramente delimitadas. Los dos comparten un amor sin límites por la madre y un rechazo por el padre. Más normal en el caso de David, ya que el suyo no es padre real, sino un padrastro que ha hecho poco por ganarse sus simpatías, pero también explicable en el caso de Pablo, a causa de la rigidez rechazante de Álvaro Galindo, rigidez que abarca a su propio hijo. Una frase de un personaje de El obispo leproso describe esta relación filial: "QQué será ese hombre, que el hijo tutea a la madre y a él le habla de usted!" (p. 853).

Otro punto de comunidad entre los dos niños es, decididamente, la postura de víctimas de la situación, postura que comparten con sus madres y que los lleva a establecer un tipo de alianza con 
ellas, como un lazo de defensa contra los otros. "Los otros", la diada padre-tía que los niños ven como un todo, pareja en perpetua amenaza.

Los dos niños son arrancados de sus madres para ser arrojados a un internado. Hay un sufrimiento en ellos en espera del alejamiento; pero, mientras los niños junto con sus madres se angustian ante la amenaza de separación, las dos tías, con el mismo sadismo, parecen regocijarse con la tensión que produce el paso de los días. De manera similar Juana y Elvira llevan con metódica precisión la cuenta de los momentos que faltan para la fecha dolorosa. La tía de David

todas las mañanas fue apuntando en el calendario los días transcurridos. Mientras éstos no llegaron a diez, hizo la operación con cierta tristeza; fue reanimándose al apuntar números de dos cifras, y al final de las vacaciones estaba más alegre que un pinzón $(D C, \mathrm{t}$. 1, p. 117).

“- ¡Aprovéchate de los veintisiete días que te quedan, porque el quince de septiembre se acabó el holgorio!" - profería la tía Elvira-. "Y veintisiete días tampoco, que si quitas el de hoy y el de ingreso....!' Desde entonces, todas las noches, antes de la cena, le presentaba el arqueo de su libertad (OL, p. 815).

Sólo me queda por señalar un pormenor más, común en las dos obras y mucho menos claramente expuesto. Me refiero a la insinuación de locura de las dos esposas, insinuación realizada por las dos parejas de hermanos, sin que parezca tener ninguna proyección fuera de los hogares ni mucha razón de existencia. Aunque tanto Clara como Paulina son dos mujeres acorraladas y profundamente infelices por su oprobioso sometimiento, no parecen en ningún momento fuera de su juicio. Las insinuaciones de sus dominadores parecen más bien provenir de la mente de éstos, aunque no estén convencidos realmente de la tal locura. Da la impresión de ser una forma más de ejercer presión, una manera de amenaza ante la posible e hipotética liberación de sus víctimas.

Aquí termina mi exposición. Mi interés se ha encaminado a demostrar una posible influencia de Dickens en Miró, una influencia no estilística, no estructural, una influencia en la forma de crear situaciones humanas.

He tratado de demostrar cómo ciertos contenidos de una obra impresionan de manera particular a un artista. De ahí nace un material nuevo que, con base en el anterior, da frutos diferentes, pero que sin duda tiene su punto de partida en el precedente. Una 
familia inglesa del siglo xIX ha dado origen a la creación de otra, de la España finisecular, en un ambiente totalmente diferente, aunque con un comportamiento semejante. La primera ha actuado como un estímulo que ha permitido el nacimiento de la segunda.

Pero lo curioso es advertir cómo ese estímulo tiene el don de hacer vibrar numerosos elementos tomados del pasado, aun lejano, de lo inconsciente, aun profundo; elementos a los que está unido por los lazos asociativos delicados y múltiples de los complejos, y que se centran a su alrededor para formar esa especie de organismo que ha de ser la obra ${ }^{9}$.

Paciencia Ontañón de Lope Universidad Nacional Autónoma de México

${ }^{9}$ Gharles Baudouin, Psicoanálisis del arte, trad. Marcos Fingent, Psique, Buenos Aires, 1972, p. 128. 